\title{
вмј Global Health Addressing disruptions in childhood routine immunisation services during the COVID-19 pandemic: perspectives from Nepal, Senegal and Liberia
}

To cite: Dixit SM, Sarr M, Gueye DM, et al. Addressing disruptions in childhood routine immunisation services during the COVID-19 pandemic: perspectives from Nepal, Senegal and Liberia. BMJ Global Health 2021;6:e005031. doi:10.1136/ bmjgh-2021-005031

Handling editor Seye Abimbola

- Additional supplemental material is published online only. To view, please visit the journal online (http://dx.doi.org/10. 1136/bmjgh-2021-005031).

Received 15 January 2021 Accepted 1 June 2021

Check for updates

C) Author(s) (or their employer(s)) 2021. Re-use permitted under CC BY. Published by BMJ.

For numbered affiliations see end of article.

\section{Correspondence to} Nancy Fullman; nancy.fullman@gatesventures. com

Sameer M Dixit, ${ }^{1}$ Moussa Sarr, ${ }^{2}$ Daouda M Gueye, ${ }^{2}$ Kyle Muther, ${ }^{3}$ T Ruston Yarnko, ${ }^{3}$ Robert A Bednarczyk, ${ }^{4}$ Adolphus T Clarke, ${ }^{5}$ Fatoumata Diakhite, ${ }^{6}$ Aliou Diallo, ${ }^{7}$ Bonheur Dounebaine, ${ }^{8}$ Shankar B Duwadi, ${ }^{8}$ Anna S Ellis, ${ }^{4}$ Nancy Fullman, ${ }^{9}$ Nathaniel Gerthe, ${ }^{9}$ Jhalak S Gautam, ${ }^{10}$ Kyra A Hester, ${ }^{4}$ Gloria Ikilezi, ${ }^{9}$ Rokhaya S Mbengue, ${ }^{11}$ Souleymane Mboup, ${ }^{2}$ Birahim P Ndiaye, ${ }^{2}$ Rajesh Man Rajbhandari, ${ }^{1}$ David E Phillips, ${ }^{9}$ Matthew C Freeman (D) 4

INTRODUCTION: SYNTHESISING LESSONS LEARNED FOR ADDRESSING COVID-19 EFFECTS ON ROUTINE IMMUNIZATION (RI) THROUGH THE EXEMPLARS IN GLOBAL HEALTH PARTNERSHIP (EGH)

RI emerged as one the most disrupted health services in early-2020 to mid-2020, ${ }^{1}$ a global systems shock associated with the COVID-19 pandemic. In May 2020, an estimated 80 million children were thought to be affected by interrupted vaccination services and campaigns, ${ }^{2}$ and over $60 \%$ of 105 countries reported at least partial RI disruptions to WHO. ${ }^{1}$ If left unaddressed, these disruptions are poised to halt or even reverse decades of global progress achieved in vaccine delivery and child health. ${ }^{34}$

Yet with great challenges can come great opportunity: knowledge and strategies gained from navigating pandemic's effects on service delivery could help pave the ways for innovation, adaptions and resilience in the ways that RI programmes are approached more broadly.

How countries have sought to address pandemic-related disruptions has undoubtedly—and rightfully—varied. The complexities of vaccine delivery and how they intersect with sociocultural mores, political commitment and technical requirements make locally relevant, tailored approaches fundamental to any successful RI programme. This is particularly true as COVID-19 continues to affect countries in different ways over time, a trend further fuelled in 2021 by unequitable

\section{Summary box}

While routine immunisation (RI) was among the health services most affected during the earlier phases of the COVID-19 pandemic, country programmes employed various mitigation strategies to maintain vaccine delivery and/or resume interrupted programming.

- Perspectives from Nepal, Senegal and Liberia highlight six key components of addressing COVID-19's effects on RI during the earlier phases of the pandemic: (1) prioritising continued services with strengthened infection prevention control; (2) engaging in effective communications and mobilisation activities, especially to offset misinformation about COVID-19 and vaccines; (3) identifying alternative locations and approaches to providing vaccine services (eg, conducting door-to-door vaccination if facility-based services were not possible); (4) instituting infection prevention controls and physical distancing measures (and adapting service provision accordingly); (5) setting up systems and strategies for reaching children who missed doses amid periods of disruption; and (6) conducting catch-up campaigns as soon as SARSCoV-2 transmission risks can be minimised.

- The ways in which COVID-19 has affected RI services have varied over time and across settings, underscoring the importance of contextually tailored mitigation efforts and adaptation, given evolving challenges amid an ongoing pandemic.

- As countries roll out COVID-19 vaccines, it will be vital to avoid one-size-fits-all implementation strategies and to support the continuance of RI services through this next phase of COVID-19 response.

COVID-19 vaccine roll-out and surges of new virus variants. Lessons learnt during earlier pandemic phases may help support health service continuity and adaptations 
throughout 2021, a challenge we will collectively face until SARS-CoV-2 is fully contained worldwide.

With this commentary, we discuss experiences from Nepal, Senegal and Liberia in addressing COVID-related disruptions of RI services in early-2020 to mid-2020. We represent a range of stakeholders brought together through the EGH partnership, an initiative focused on identifying lessons learnt from positive outliers in global health and harnessing the expertise of programme leaders, researchers and funders to better understand what underpins health gains and implementation success. ${ }^{5-7}$ As such, our perspectives may not be shared by others in RI programmes for a given context; further, they may not represent challenges and/or mitigation strategies occurring now.

\section{MAIN TYPES OF PANDEMIC-RELATED EFFECTS ON RI AND APPROACHES TO MITIGATION}

The COVID-19 pandemic affected key determinants of vaccination-facility readiness, intent to vaccinate and community access 89 -as well as how these drivers interact together to support timely, effective vaccine services worldwide (table 1). On their own, each of these disruptions could negatively impact vaccination rates; in combination, they formed substantial obstacles to RI programmes as a whole.

In Nepal, about $50 \%$ of immunisation centres ceased operations during the initial onset of lockdown measures at the end of March 2020; furthermore, cases among healthcare workers would cause clinics to abruptly suspend services. In mid-April 2020, a nationwide measles-rubella campaign was suspended due to safety concerns. Measles outbreaks occurred in 4 of Nepal's 77 districts, which were thought to be related to such disruptions.

For Senegal, with mass gatherings prohibited in midMarch 2020, vaccination activities and mobilisation efforts led by Badiènou Gokh and other communitybased health workers had to be postponed. Human papillomavirus (HPV) vaccine delivery was halted as schools, Senegal's main platform for HPV vaccination, closed. At facilities, health worker availability became constrained by concurrent deployment for COVID-19 management and response. Senegal also saw patient attendance fall, which was attributed to a combination of movement restrictions, concerns about COVID-19 exposure, and/or rumours about COVID-19 and vaccine reliability.

In Liberia, growing vaccine hesitancy emerged as a major challenge, with rumours rapidly spreading about COVID-19 vaccines being tested on citizens. Concerned about potential longer-term consequences of vaccine misinformation, Liberia temporarily halted facility-based outreach services. Uptake of RI services also declined during the earlier days of Liberia's state of emergency, while health facility staff also faced inadequate supplies of personal protective equipment (PPE).
These represent only a fraction of RI disruptions experienced in 2020, ${ }^{1}{ }^{2} 10$ underscoring the importance of swiftly implementing catch-up activities and closing gaps in coverage. WHO has issued recommendations on providing immunisation services during the pandemic, ${ }^{11-14}$ with its guidance evolving alongside world's evidence base on COVID-19 and how to weigh the relative risks of SARS-CoV-2 transmission against the costs of service disruption. In late March 2020, for countries with surging infections and without active measles or polio outbreaks, WHO recommendations viewed exposing healthcare workers and community members to the novel coronavirus as greater than temporarily postponing mass campaigns. ${ }^{11}$ As the world's understanding of COVID-19 improved and the magnitude of service disruptions began to surface, ${ }^{2}$ WHO issued follow-up guidance on implementing mass vaccination campaigns ${ }^{12}$ and principles for maintaining or resuming RI. ${ }^{13} 14$

How countries have then acted-adapting such guidelines for local needs or developing their own mitigation strategies against COVID-19 disruptions based on prior experience or some combination of each-has become an area of great interest. Drawing from experiences in Nepal, Senegal and Liberia, as well as desk research, we identified six main components to approaches for addressing pandemic-related effects on RI (table 2).

First, prioritising the continuity of RI services, at both national and local levels, was a key component. This was particularly evident in Nepal, where the Ministry of Health and Population directed its Family Welfare Division to implement safety protocols and to adapt service provision as necessary to maintain RI services amid the country's extended lockdown period (ie, end of March through most of July 2020).

Second, implementing communications and outreach activities were vital for addressing misinformation and strengthening trust in both COVID-19 guidance and RI activities. Such work was the cornerstone to Liberia's mitigation approach, with a vaccine perception study identifying myths about COVID-19, limited trust in both new and old vaccines, and delays in vaccination timeliness as the primary barriers to uptake. In collaboration with key partners, Liberia's Expanded Programme on Immunization (EPI) then developed a multistage communications plan, mapping key messages to target audiences, communication channels, and impact metrics for short-term, medium-term and long-term objectives.

Third, identifying alternative delivery options beyond health clinic settings was critical for promoting service continuity during the COVID-19 pandemic. For instance, Senegal's RI programme began offering vaccine sessions at alternative hours, including after work and during weekends, and community health workers conducted home visits for HPV vaccination after school-based services became unavailable amid widespread closures.

Fourth, instituting IPC and distancing measures while modifying service provision practices has been fundamental for maximising the safe continuance or 
Table 1 Summary of main types of pandemic-related disruptions for childhood Rl, by vaccination driver, with global examples and reports from Nepal, Senegal and Liberia

\begin{tabular}{|c|c|c|}
\hline \multicolumn{3}{|l|}{ Vaccination driver } \\
\hline Facility readiness & Intent to vaccinate & Community access \\
\hline \multicolumn{3}{|l|}{ Vaccination driver definition } \\
\hline $\begin{array}{l}\text { Health system supply and capacity, via } \\
\text { health facilities, to adequately meet the } \\
\text { demand of patients who seek vaccine } \\
\text { services }\end{array}$ & $\begin{array}{l}\text { Demand for vaccine services by caretakers that, } \\
\text { in the absence of all other barriers, would result in } \\
\text { children being vaccinated }\end{array}$ & $\begin{array}{l}\text { Ability to carry out vaccination via barriers } \\
\text { and facilitators between facility readiness } \\
\text { and vaccination intent }\end{array}$ \\
\hline \multicolumn{3}{|c|}{ Examples of documented disruptions related to COVID-19 } \\
\hline $\begin{array}{l}\text { Delayed shipments of vaccine } \\
\text { stocks and key supplies due to } \\
\text { travel restrictions and reduced flight } \\
\text { availability. } \\
\text { Reduced or halted service availability } \\
\text { and/or hours of operation. } \\
\text { Inadequate PPE, sanitation and } \\
\text { infection control supplies. } \\
\text { Deployment of staff for COVID-19 } \\
\text { response. }^{19} \\
\text { Staff shortages due to COVID-19 } \\
\text { infections, fear of exposure and/or } \\
\text { burnout. }\end{array}$ & $\begin{array}{l}\text { Fear of virus exposure at healthcare settings. } \\
\text { Individuals instructed to postpone or delay } \\
\text { non-urgent healthcare services due to } \\
\text { concerns about overburdening healthcare } \\
\text { facilities. } \\
\text { Misinformation or rumours on COVID-19 and } \\
\text { vaccination safety. }\end{array}$ & $\begin{array}{l}\text { Postponement or cancellation of mass } \\
\text { vaccination campaigns, as well as new } \\
\text { vaccine introductions. } \\
\text { Restrictions on movement outside of } \\
\text { residences and physical access to } \\
\text { vaccine services due to social distancing } \\
\text { policies and lockdown measures enacted } \\
\text { to curb viral transmission. }\end{array}$ \\
\hline \multicolumn{3}{|c|}{ Country-reported types of disruptions (via Exemplars in Global Health ${ }^{5}$ ) } \\
\hline \multicolumn{3}{|l|}{ Nepal } \\
\hline $\begin{array}{l}50 \% \text { of the country's immunisation } \\
\text { service centres ceased operations after } \\
\text { lockdown measures were enacted at } \\
\text { the end of March } 2020 \text { (ie, from } 16000 \\
\text { to } 8000 \text { ). } \\
\text { Hospitals, inclusive of their outpatient } \\
\text { departments, shut down frequently from } \\
\text { COVID-19 cases among healthcare } \\
\text { professionals. }\end{array}$ & & $\begin{array}{l}\text { Nepal halted measles-rubella campaign ir } \\
\text { mid-April } 2020 \text { due to safety concerns. }\end{array}$ \\
\hline \multicolumn{3}{|l|}{ Senegal } \\
\hline $\begin{array}{l}\text { Health centre staff were tasked with } \\
\text { COVID-19 management and response, } \\
\text { reducing their availability for other } \\
\text { services. }\end{array}$ & $\begin{array}{l}\text { Patient attendance substantially declined } \\
\text { for vaccine services, and some caretakers } \\
\text { refused care when home visits were offered by } \\
\text { community workers in full PPE. } \\
\text { Rumours spread about an 'eventual evil' } \\
\text { COVID-19 vaccine trial in the country. }\end{array}$ & $\begin{array}{l}\text { School closures halted school-based } \\
\text { human papillomavirus service delivery. } \\
\text { Mass gatherings were prohibited } \\
\text { in mid-March 2020, postponing } \\
\text { community-based outreach activities and } \\
\text { mobilisation. }\end{array}$ \\
\hline \multicolumn{3}{|l|}{ Liberia } \\
\hline $\begin{array}{l}\text { Health facility-based outreach activities } \\
\text { were suspended. } \\
\text { Initial gaps in PPE availability for staff } \\
\text { occurred. }\end{array}$ & $\begin{array}{l}\text { Growing vaccine hesitancy took place, fuelled } \\
\text { by rumours of COVID-19 vaccines being tested } \\
\text { on citizens. }\end{array}$ & $\begin{array}{l}\text { Early days of the country's state of } \\
\text { emergency and curfew were associated } \\
\text { with declines in the uptake of RI services. }\end{array}$ \\
\hline
\end{tabular}

Vaccination driver definitions are adapted from the Phillips and colleagues' framework on determinants of vaccination. ${ }^{89}$ Reported pandemic-related disruptions in Nepal, Senegal and Liberia are based on information provided by coauthors via direct correspondence and responses provided through guided interviews (online supplemental file 1).

EPI, Expanded Programme on Immunization; PPE, personal protective equipment; RI, routine immunisation.

resumption of vaccination services. Nepal, Senegal and Liberia each adapted WHO guidelines to national and local settings, conducted IPC trainings and procured PPE for vaccinators.

Fifth, leveraging current-or setting up-systems to track missed doses and target catch-up efforts remains crucial for RI recovery efforts. In Senegal, healthcare workers have been using contact records maintained at district offices to text or phone parents whose children missed immunisation visits. In the absence of such information, short-term delays in completing vaccination schedules could quickly turn into more persistent coverage gaps and higher risk for vaccine-preventable disease.

Sixth, conducting catch-up RI services and campaigns as soon as SARS-CoV-2 transmission risks could be mitigated is imperative to addressing pandemic-related disruptions. For instance, Nepal resumed its nationwide 


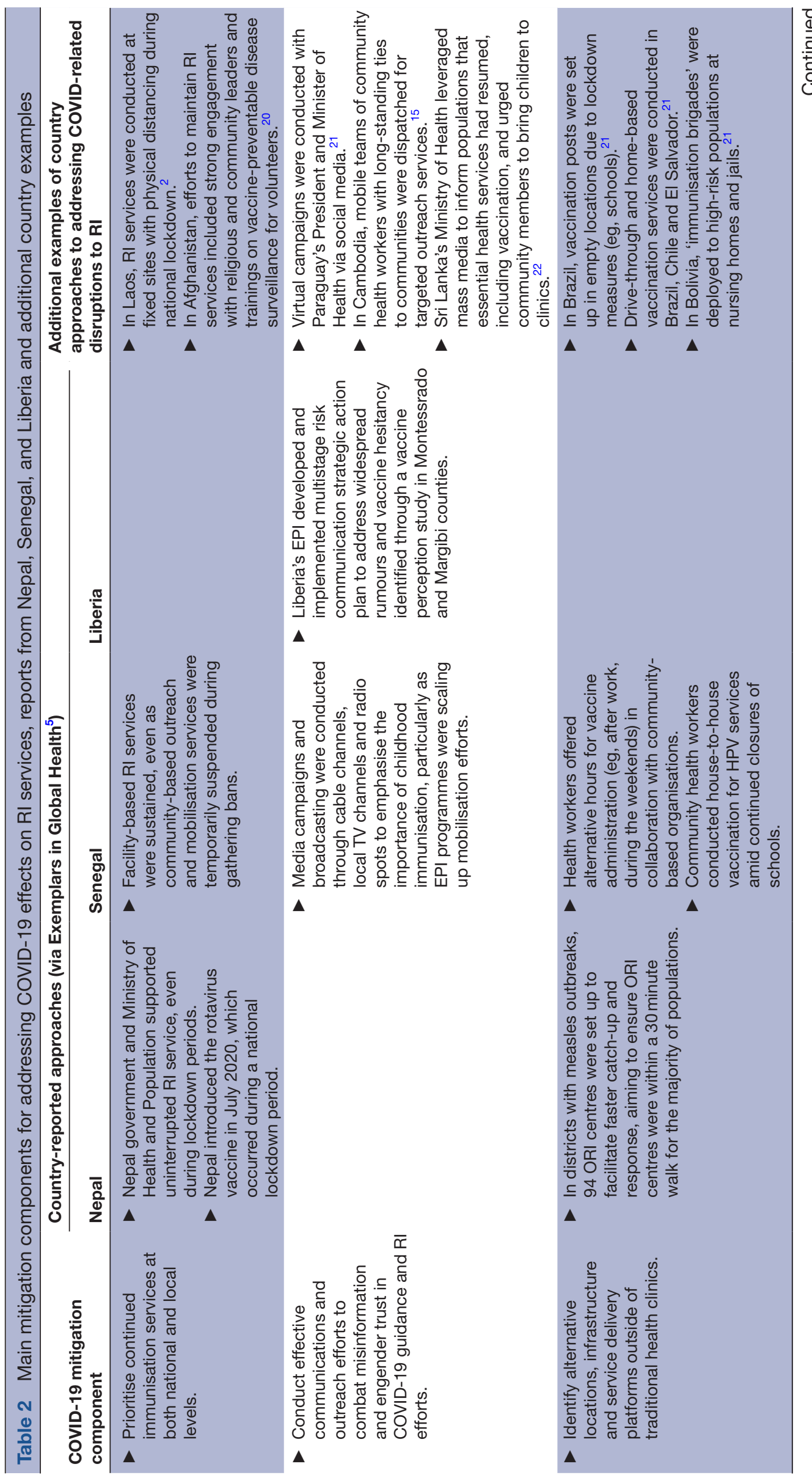




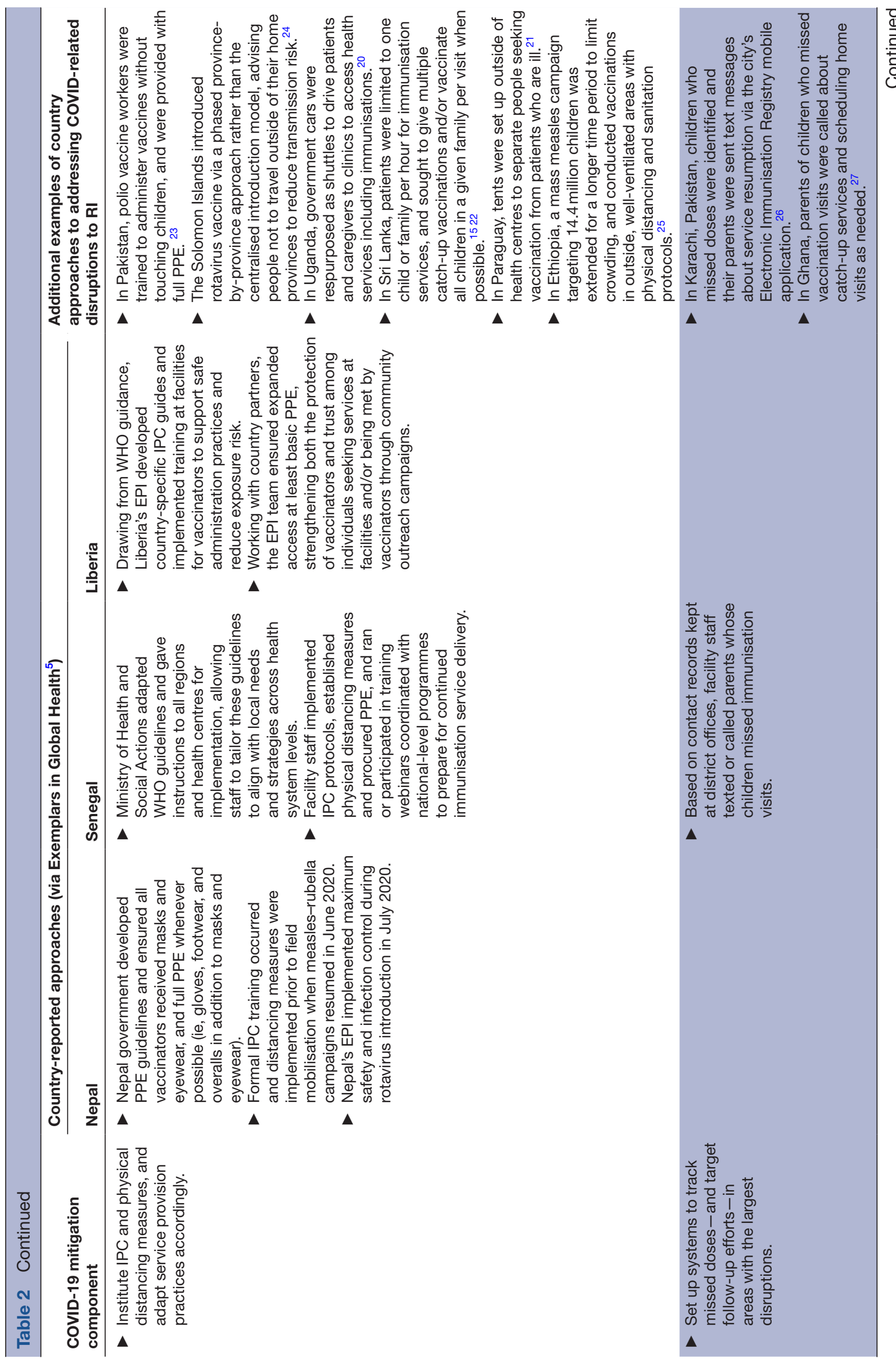




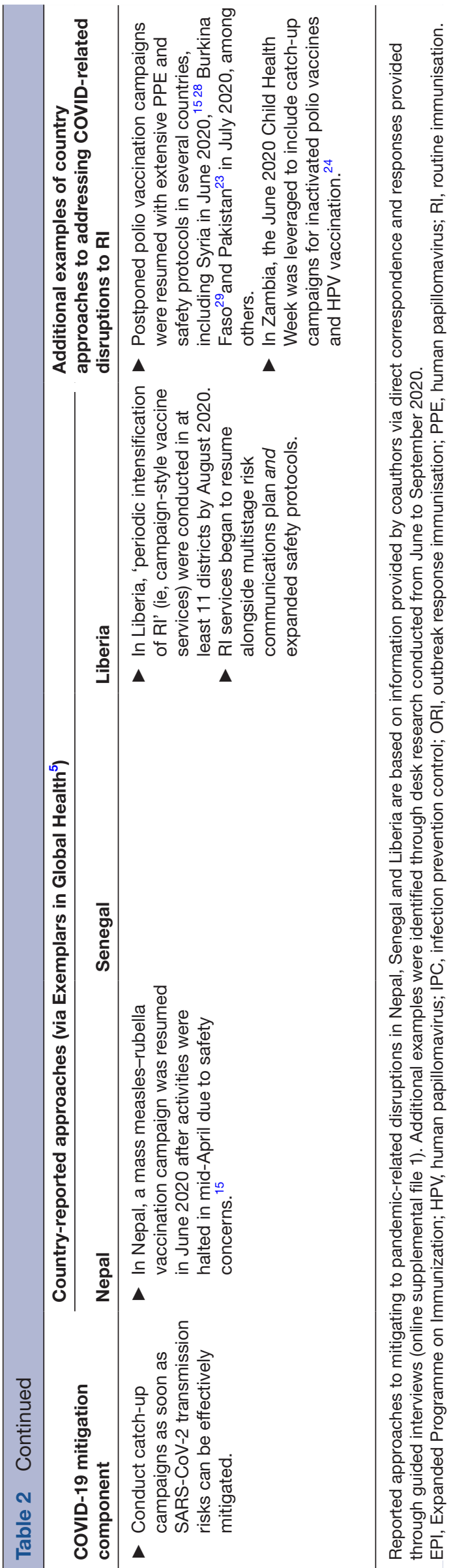

measles-rubella mass campaign in June 2020 after a 1.5-month pause, ${ }^{15}$ and by August 2020, Liberia had conducted periodic intensification of RI in at least 11 districts.

Not every approach was used or perhaps needed in each country, just as COVID-19 has affected RI services in different ways across settings. For instance, Liberia's EPI had to weigh the potential consequences of rapidly deteriorating vaccine confidence and trust against temporarily suspending facility-based outreach services in April 2020. Their pivot to identifying obstacles to vaccine uptake and establishing their risk communications strategy before resuming services again involved distinct planning and implementation approaches from those required elsewhere. In Nepal, large numbers of people would still show up at immunisation centres to vaccinate their children during lockdown periods; while high vaccine acceptance and service-seeking typically would be welcome, during the ongoing COVID-19 pandemic, such turn-out could heighten potential virus exposure and transmission risk in the absence of clear distancing measures and IPC protocols. As such, Nepal had to carefully coordinate immunisation sessions to maximise safety, especially when the rotavirus vaccine was introduced in July 2020. For Senegal, adapting modes of RI delivery was central to mitigating COVID-related effects on immunisation, especially when typical RI platforms-community-based outreach and school-based services-were not viable during nationwide gathering restrictions and closures. In response, community health workers have gone houseto-house for vaccination visits and have sought to provide greater flexibility in visit timing. What unites these diverse settings and programmes is the recognition that each level of vaccination barriers or facilitators must be addressed, from patient acceptance and trust to community access; the willingness to adapt to and test alternative approaches; and the overarching dedication to providing RI to all.

It is worth noting that pandemic-related impacts on RI may not be wholly known for months or even years to come. Similarly, the longer-term success of past and present efforts to maintain or resume RI remains unclear; this is particularly true as epidemic trajectories continue to change and now many countries are rapidly deploying COVID-19 vaccines alongside new virus variants and corresponding surges. Going forward, it is crucial to better understand implementation dimensions of modified RI services, including acceptability, feasibility, costs and effectiveness, ${ }^{16} 17$ especially as EPI programmes consider if and how to resume prepandemic operations. As more data are collected, analysed and disseminated, through the EGH partnership, we hope to continue collating lessons learnt about programmatic strategies and innovations that countries implemented to sustain vaccine delivery during the COVID-19 crisis. 


\section{CONCLUSIONS}

The COVID-19 pandemic has threatened progress made in child health worldwide, posing widespread disruptions and challenges to RI programmes, healthcare providers and patients alike. Lessons learnt through this global crisis are only as beneficial as efforts to collaborate and rethink approaches to promoting resilience, equity, and sustainability for both RI programmes and preparedness more broadly. The world now faces its next reckoning with COVID-19: deployment of COVID-19 vaccines amid ongoing, or even surging, SARS-CoV-2 transmission. How we collectively approach RI services and vaccine campaigns, from local to global levels, will ultimately determine how the remainder of this pandemic will unfold.

\section{Author affiliations}

${ }^{1}$ Center for Molecular Dynamics Nepal, Kathmandu, Nepal

${ }^{2}$ Institut de Recherche en Santé de Surveillance Epidémiologique et de Formations, Dakar, Senegal

${ }^{3}$ Last Mile Health, Monrovia, Liberia

${ }^{4}$ Rollins School of Public Health, Emory University, Atlanta, Georgia, USA

${ }^{5}$ Expanded Programme on Immunisation, Republic of Liberia Ministry of Health, Monrovia, Liberia

${ }^{6}$ Focal Point for EPI and Surveillance Activities, Health Center of Rufisque, Dakar, Senegal

${ }^{7}$ Expanded Programme on Immunisation Unit, WHO Country Office Senegal, Dakar, Senegal

${ }^{8}$ Health Section Chief, Benighat, Nepal

${ }^{9}$ Gates Ventures, Kirkland, Washington, USA

${ }^{10}$ Child Health and Immunization Section, Family Welfare Division, Department of Health Services, Ministry of Health and Population, Kathmandu, Nepal

${ }^{11}$ Focal Point for EPI and Surveillance Activities, Health Center, Philip Maguilene Senghor of Yoff, Dakar, Senegal

Acknowledgements We would like to acknowledge Nepal's Ministry of Health and Population and the WHO Nepal Immunization Preventable Diseases section, Senegal's Ministry of Health and Social Actions and the WHO Country Office in Senegal, and Liberia's Ministry of Health. The Exemplars in Global Health programme is a partnership including the institutional affiliations of the authors listed here as well as country research partners. The authors acknowledge contributions of all partners involved, which also include country leadership overseeing research collaborations; Anna Rapp and Ethan Wong of the Bill \& Melinda Gates Foundation; and Daniel Beaulieu, Niranjan Bose and Oliver Rothschild at Gates Ventures. We also thank Angela Hwang for her perspectives and feedback on routine immunisation programmes and drafting of the manuscript. The Exemplars in Global Health Vaccine Delivery project, coordinated by Emory University, is funded by the Bill \& Melinda Gates Foundation in conjunction with Gates Ventures.

Contributors SMD, MS, DMG, KM and TRY contributed equally as first authors on this manuscript. DEP and MCF contributed equally as senior authors on this manuscript. All other authors contributed to providing program perspectives or desk research, synthesizing findings, initial drafting, critical review and feedback, and/or finalisation of the first submission of this manuscript.

Funding This article was funded by Bill and Melinda Gates Foundation.

Competing interests $\mathrm{RAB}, \mathrm{KAH}$ and MCF are recipients of funding from the Bill \& Melinda Gates Foundation. MCF is a recipient of funding from Gates Ventures and serves in an unpaid role on a Gates Ventures advisory board. NF, NG, Gl and DEP are employees of Gates Ventures. NF received funding as a WHO consultant from June-September 2019. Authors declare no additional interests.

Patient consent for publication Not required.

Provenance and peer review Not commissioned; externally peer reviewed.

Data availability statement All data relevant to the study are included the article.

Supplemental material This content has been supplied by the author(s). It has not been vetted by BMJ Publishing Group Limited (BMJ) and may not have been peer-reviewed. Any opinions or recommendations discussed are solely those of the author(s) and are not endorsed by BMJ. BMJ disclaims all liability and responsibility arising from any reliance placed on the content. Where the content includes any translated material, BMJ does not warrant the accuracy and reliability of the translations (including but not limited to local regulations, clinical guidelines, terminology, drug names and drug dosages), and is not responsible for any error and/or omissions arising from translation and adaptation or otherwise.

Open access This is an open access article distributed in accordance with the Creative Commons Attribution 4.0 Unported (CC BY 4.0) license, which permits others to copy, redistribute, remix, transform and build upon this work for any purpose, provided the original work is properly cited, a link to the licence is given, and indication of whether changes were made. See: https://creativecommons.org/ licenses/by/4.0/.

\section{ORCID iD}

Matthew C Freeman http://orcid.org/0000-0002-1517-2572

\section{REFERENCES}

WHO. Pulse survey on continuity of essential health services during the COVID 19 pandemic: interim report. Geneva, Switzerland WHO 2020. https://www.who.int/publications-detail-redirect/WHO-2019nCoV-EHS continuity-survey-2020.1 [Accessed 04 Sep 2020].

2 UNICEF. At least 80 million children under one at risk of diseases such as diphtheria, measles and polio as COVID-19 disrupts routine vaccination efforts, warn Gavi, who and UNICEF, 2020. Available: https://www.unicef.org/press-releases/least-80-million-childrenunder-one-risk-diseases-such-diphtheria-measles-and-polio [Accessed 03 Aug 2020].

3 Bill \& Melinda Gates Foundation (BMGF). 2020 Goalkeepers report COVID-19: a global perspective. Seattle, WA, USA: BMGF, 2020. https://www.gatesfoundation.org/goalkeepers/report/2020-report

4 Causey K, Fullman N, Sorensen RJ, et al. Estimating global and regional disruptions to routine childhood vaccine coverage during the COVID-19 pandemic in 2020: a modelling study. The Lancet $2021 ; 398$.

5 Exemplars in Global Health. Exemplars.health. Available: https:// www.exemplars.health/ [Accessed 03 Sep 2020]

6 Carter A, Akseer N, Ho K, et al. A framework for identifying and learning from countries that demonstrated exemplary performance in improving health outcomes and systems. BMJ Glob Health 2020;5:e002938.

7 Phillips DE, Bhutta ZA, Binagwaho A, et al. Learning from exemplars in global health: a road map for mitigating indirect effects of COVID-19 on maternal and child health. BMJ Glob Health 2020;5:e003430.

8 Phillips DE, Dieleman JL, Lim SS, et al. Determinants of effective vaccine coverage in low and middle-income countries: a systematic review and interpretive synthesis. BMC Health Serv Res 2017;17:681.

9 Phillips DE, Dieleman JL, Shearer JC, et al. Childhood vaccines in Uganda and Zambia: determinants and barriers to vaccine coverage. Vaccine 2018;36:4236-44.

10 World Health Organization (WHO). Second round of the National pulse survey on continuity of essential health services during the COVID-19 pandemic: January-March 2021. interim report. Geneva, Switzerland: WHO, 2021. https://www.who.int/publications/i/item/ WHO-2019-nCoV-EHS-continuity-survey-2021.1

11 World Health Organization (WHO). Guiding principles for immunization activities during the COVID-19 pandemic: interim guidance. Geneva, Switzerland: WHO, 2020. https://www.who.int/ publications-detail-redirect/guiding-principles-for-immunizationactivities-during-the-covid-19-pandemic-interim-guidance

12 World Health Organization (WHO). Framework for decision-making: implement of mass vaccination campaigns in the context of COVID-19. interim guidance. Geneva, Switzerland: WHO, 2020. https://apps.who.int/iris/bitstream/handle/10665/332159/WHO 2019-nCoV-Framework_Mass_Vaccination-2020.1-eng.pdf

13 World Health Organization (WHO). Maintaining essential health services: operational guidance for the COVID-19 context interim guidance. Geneva, Switzerland: WHO, 2020. https://www.who.int/ publications/i/item/WHO-2019-nCoV-essential-health-services2020.1

14 World Health Organization (WHO). Immunization as an essential health service: guiding principles for immunization activities during the COVID-19 pandemic and other times of severe disruption. Geneva, Switzerland: WHO, 2020. https://www.who.int/publications/ i/item/immunization-as-an-essential-health-service-guiding- 
principles-for-immunization-activities-during-the-covid-19pandemic-and-other-times-of-severe-disruption

15 World Health Organization (WHO). How WHO is supporting ongoing vaccination efforts during the COVID-19 pandemic, 2020. Available: https://www.who.int/news-room/feature-stories/detail/how-whois-supporting-ongoing-vaccination-efforts-during-the-covid-19pandemic [Accessed 04 Aug 2020].

16 Glasgow RE, Estabrooks PE. Pragmatic applications of RE-AIM for health care initiatives in community and clinical settings. Prev Chronic Dis 2018;15:E02.

17 Damschroder LJ, Aron DC, Keith RE, et al. Fostering implementation of health services research findings into practice: a consolidated framework for advancing implementation science. Implement Sci 2009;4:50.

18 UNICEF. Geneva Palais briefing note on the impact of COVID-19 mitigation measures on vaccine supply and logistics, 2020. Available: https://www.unicef.org/press-releases/geneva-palaisbriefing-note-impact-covid-19-mitigation-measures-vaccine-supplyand [Accessed 03 Aug 2020].

19 BrandRoom I net. Missed a vaccine? It's time to bounce back! INQUIRER.net, 2020. Available: https://globalnation.inquirer.net/ 190451/missed-a-vaccine-its-time-to-bounce-back [Accessed 11 Dec 2020].

20 Gavi, the Vaccine Alliance. COVID-19 situation report 9. Geneva, Switzerland: Gavi, 2020. https://www.gavi.org/sites/default/files/ document/2020/Gavi-COVID-19-Situation-Report-9-05192020 0.pdf

21 Pan American Health Organization (PAHO). PAHO urges countries to maintain vaccination during COVID-19 pandemic, 2020. Available: http://www.paho.org/en/news/26-4-2020-paho-urges-countriesmaintain-vaccination-during-covid-19-pandemic [Accessed 04 Aug 2020].

22 Putting women and children first: immunization resumes in Sri Lanka amidst the COVID-19 pandemic. Available: https://www.who.int/ southeastasia/news/feature-stories/detail/putting-women-andchildren-first-immunization-resumes-in-sri-lanka-amidst-the-covid19-pandemic [Accessed 11 Dec 2020].

23 Gadzo M. Pakistan resumes polio vaccinations after coronavirus hiatus. Available: https://www.aljazeera.com/news/2020/07/ pakistan-resumes-polio-vaccinations-coronavirus-hiatus200720071328769.html [Accessed 04 Aug 2020].

24 Gavi, the Vaccine Alliance. COVID-19 situation report 13. Geneva, Switzerland: Gavi, 2020. https://www.gavi.org/sites/default/files/ covid/Gavi-COVID-19-Situation-Report-13-20200714.pdf

25 WHO Reg. Off. Afr. Ethiopia vaccinates nearly 15 million children against measles despite COVID-19 challenges. Available: https:// www.afro.who.int/news/ethiopia-vaccinates-nearly-15-millionchildren-against-measles-despite-covid-19-challenges [Accessed 11 Dec 2020].

26 Chandir S, Siddiqi DA, Setayesh H, et al. Impact of COVID-19 lockdown on routine immunisation in Karachi, Pakistan. Lancet Glob Health 2020;8:e1118-20.

27 WHO Reg. Off. Afr. Ghana's community nurses deliver child health care amid COVID-19. Available: https://www.afro.who.int/news/ ghanas-community-nurses-deliver-child-health-care-amid-covid-19 [Accessed 11 Dec 2020].

28 Gavi, the Vaccine Alliance. Delivering life-saving vaccines during the COVID-19 pandemic, 2020. Available: https://www.gavi.org/ vaccineswork/delivering-life-saving-vaccines-during-covid-19pandemic [Accessed 07 Aug 2020].

29 WHO Reg. Off. Afr. Burkina Faso resumes polio vaccination campaigns under strict COVID-19 prevention measures. Available: https://www.afro.who.int/news/burkina-faso-resumes-poliovaccination-campaigns-under-strict-covid-19-prevention-measures [Accessed 11 Dec 2020]. 